This is a self-archived version of an original article. This version may differ from the original in pagination and typographic details.

Author(s): Pitkänen-Huhta, Anne

Title: Multilingualism in (Foreign) Language Teaching and Learning

Year: 2019

Version: Accepted version (Final draft)

Copyright: (c) 2019 Taylor \& Francis

Rights: In Copyright

Rights url: http://rightsstatements.org/page/InC/1.0/?language=en

Please cite the original version:

Pitkänen-Huhta, A. (2019). Multilingualism in (Foreign) Language Teaching and Learning. In G. Barkhuizen (Ed.), Qualitative Research Topics in Language Teacher Education (pp. 137-142).

Routledge. https://doi.org/10.4324/9780429461347-23 


\title{
Multilingualism in (foreign) language teaching and learning
}

\author{
Anne Pitkänen-Huhta \\ University of Jyväskylä, Finland
}

I am an applied linguist who considers language learning to be a socially constructed practice. In fact, I would rather talk about applied language studies than applied linguistics, as I understand this area of inquiry to include any language related research that bears a strong connection to societally significant phenomena. In that broad palette of research, my own work would be placed at the interface of the areas of language learning and teaching, on the one hand, and discourse studies and sociolinguistics, on the other. I have always worked with students who wish to be language teachers. Over the years, I have seen hundreds of students entering working life that is in constant turmoil. My principal interest is therefore in the changing conditions of language learning, in the diversity of learners, and in the societal and personal push and pull forces under which teachers and learners have to create meaningful practices.

A note on the terminology I use in this chapter is needed here. I am fully aware of the complexities of placing languages into the categories of mother tongue, first, second, foreign, and so on, as language use keeps taking new shapes in the changing world. I will nevertheless use here the term foreign language when I talk about the languages that are typically learnt and taught in classrooms and which people use to varying degrees in work, study and leisure contexts, since our educational systems are still build around categorizing languages as school subjects with specific labels such as mother tongue or foreign languages. 


\section{Strategies for choosing a topic}

When starting to think about how I have identified my research topics, I noticed that the processes are, in fact, a great mystery to me. It is impossible for me to give a good recipe for finding and choosing topics but what I can do is to suggest a few ingredients that seem to work for me and that sometimes have resulted in a very interesting meal. I will briefly discuss four ingredients that work for me. I do not present the ideas in any order of importance or preference.

Team work has always been the core of my research activities. I have had the pleasure of having very resourceful and invigorating colleagues with whom to share and create wild ideas. This might be a cliché but I still firmly believe that the best and most innovative ideas for research are born in informal discussions in coffee rooms and corridors. I therefore encourage people to engage in idle talk around societally interesting and topical issues that may lead to important research questions.

Cross fertilization is something that arises from team work when you build on the coffee room discussions in a more organized way in seminars and conferences both in your own organization as well as in national and international gatherings. New ideas often arise from the most unexpected combinations of research areas.

Media is an excellent source of ideas; follow the current discussions and debates on issues related to language. As an example, one could mention the concern in Finnish media over the lack of diversity in the language reserve of Finland. Fewer and fewer school children choose to study languages other than English and thus proficiency in languages often means proficiency in English only. Experts especially from commerce and manufacturing are making worrying statements about Finns losing the edge on international markets because of a lack of skills in 
languages other than English. So, this kind of discussion gives researchers plenty of topics for research from different angles.

None of the above work unless you practice constant critical self-reflection. Observe your own teaching or a colleague's teaching, relate your observations to changes in the world, read research literature beyond SLA, language learning, teacher education, and analyze your own experiences.

\section{Current research topics}

Increasing multilingualism has important repercussions for (language) education (e.g., Cenoz \& Gorter, 2011; Douglas Fir Group, 2016; May, 2014). In Europe, in particular, classrooms have become more and more multilingual and multicultural in recent decades. This area is, however, relevant also in contexts where multilingualism has always been present. Research has focused on second language learners or on heritage language maintenance in second language contexts, but what has been almost completely ignored are foreign language contexts. There have, however, been some concerned voices about the neglected area of the relationship between multilingualism and foreign language learning and teaching (e.g., Kramsch, 2014; Lo Bianco, 2014) but very little empirical research.

\section{Multilingual learners in foreign language classroom}

The increasingly diverse linguistic repertoires evident in classrooms makes foreign language learning a complex matter. Therefore, the relationship between learners, teachers, and the languages present in the classroom has to be examined. Learners' cultural and linguistic backgrounds have an effect on how they relate to the foreign language being taught. The language in question may have quite a different sociolinguistic status in the lives of different 
learners, and the learners' experiences related to the language may differ as well. Teachers, on the other hand may struggle with how to recognize, acknowledge and make use of all languages present in the classroom.

In researching this topic, it is crucial to get insight into the lived experiences of learners and teachers, and therefore to adopt methods that help researchers' unravel the inner feelings of the research participants. The experiences and feelings could be captured through verbal and visual narratives, for example, that would prompt the participants to share their experiences (e.g., Kalaja \& Pitkänen-Huhta, 2018).

\section{Teaching practices in a multilingual group}

Very often learners in the foreign language classroom are assumed to be monolingual speakers of the same language. Although this is not the case anymore, it is still often considered that the learners' linguistic backgrounds do not have consequences for how the foreign language is taught. If problems are encountered, the solution is to resort to monolingualism, that is, to use the target language only. As with the previous topic, it is important to study both teacher and learner perspectives. The most direct way to study teaching practices is to observe classrooms. To connect observation to teacher and learner experiences, it would be beneficial to engage in collaborative work with both teachers and learners during data collection as well as data analysis.

\section{Teaching/learning materials for multilingual groups}

Learning materials play an important role in shaping classroom teaching and learning practices, and therefore it is crucial to study materials as well. Materials have typically been designed with the assumption that all learners share the first language. An example from the European context are textbooks in Finland. Finland has very strong markets for textbooks, they are generally very 
good, and they are expected to reflect the National Core Curricula. But still today, the foreign languages are taught mostly through Finnish. The student needs to know Finnish to understand the instructions in tasks, and wordlists have translations in Finnish. Those whose Finnish skills are not up to the level of first language are at a disadvantage. For this research topic the most appropriate method would be textbook analysis, but I would suggest that it would be complemented with teacher and student interviews. This would give more insight into how materials are used in the classroom. One possible extension of these methods would be to initiate research on learning materials in teacher training and thereby to involve future teachers in materials development.

\section{Discourses of multilingualism/monolingualism in policy documents}

Policy documents such as curricula form the basis of teaching and learning in the classroom. It is therefore crucial to examine what kinds of explicit and implicit conceptualizations of multilingualism (or perhaps monolingualism) they hold. What the crucial documents are depends on the context of study. It might be national curricula, school specific curricula and policies, individual classroom policies, assessment practices, teaching materials, or media discussions on schools and teaching. The appropriate research method for this topic depends on the kinds of discourses that are relevant to study. It could be textual and (critical) discourse analysis of documents, observation, interviews, and so on.

\section{Teacher's conceptualizations of language vs. their teaching practices}

What the teacher does in the classroom is crucial for their learners to learn and what the teacher does is based on her/his understanding of the goal and means of teaching, i.e. language. It is important to approach this topic from several angles, as it is vital to understand what the 
conceptualizations are, where they come from, and how they are enacted in classroom practices. The methods could include teacher interviews, focus group interviews, questionnaires, visual and verbal narratives, and visualizations as prompts for further discussion. These would have to be contrasted with observed (video-recorded) classroom practices and teacher reflection on the observed practices.

\section{Research questions}

1. How do teachers recognize and acknowledge multilingual learners in their foreign language classrooms?

To create meaningful practices for all learners in the classroom, teachers would need to know their students' cultural and linguistic backgrounds and make use of the potential of multilingualism in their classrooms.

2. How do learners see their multilingualism in relation to learning a foreign language? Is it beneficial for learning? Does it hinder learning?

It is equally important to know how learners themselves recognize their cultural and linguistic background and how they are able to connect that to the learning of new languages.

3. How do foreign language teachers take multilingual learners into account in their teaching practices?

Taking multilingualism into account in classroom practices is a very complex issue, and therefore we need to know if teachers do this in practice and how they do it. 
4. How do 'monolingual' or the majority language speakers in foreign language classrooms benefit from teaching practices that take into account multilingual learners?

It should be self-evident that adopting classroom practices that are culture and language sensitive are beneficial for all learners, but how exactly this takes place in foreign language learning is not known.

5. How is multilingualism evident in foreign language learning materials? As materials are often the primary gatekeeper in the classroom, it is paramount to know if and how different foreign language learning materials take multilingualism into account.

6. How do teaching materials support multilingual learners?

As a follow-up to the previous question, this question would take a closer look at the mechanisms of support in the materials.

7. How does multilingualism feature in specific policy documents related to language education?

This question connects grassroots practices to broader societal structures and examines how ideas of multilingualism are spread from the top down.

8. How do teachers understand the concept of language?

If we find an answer to this question, we will better understand how languages are taught in the classrooms.

9. What are the sources of teachers' conceptualizations of language? 
Teachers formulate their conceptualizations from different sources, including their own experiences, their education and teacher training, policy documents, materials, and the media. To be able to improve teacher education, we need to know what these sources are.

10. How do conceptualizations of language reflect the teaching practices of specific teachers? This question combines the two previous questions and digs deeper into the relationship between conceptualizations and actual classroom teaching and learning practices.

\section{References}

Cenoz, J., \& Gorter D. (2011). A holistic approach to multilingual education: Introduction. The Modern Language Journal, 95(3), 339-343.

Douglas Fir group. (2016). A transdisciplinary framework for SLA in a multilingual world. The Modern Language Journal, 100S, 19-47.

Kalaja, P., \& Pitkänen-Huhta, A. (2018). ALR special issue: Visual methods in applied language studies. Applied Linguistics Review, 9(2-3), 157-176.

Kramsch, C. (2014). Teaching foreign languages in an era of globalization: Introduction. The Modern Language Journal, 98(1), 296-311.

Lo Bianco, J. (2014). Domesticating the foreign: Globalization's effects on the place/s of languages. The Modern Language Journal, 98(1), 312-325.

May, S. (Ed.). (2014). The multilingual turn: Implications for SLA, TESOL and bilingual education. New York \& London: Routledge. 